\title{
猕猴卵母细胞的体外成熟、受精和培养*
}

\author{
季维智陈建春杨上川 部如金、商恩缘保海仙 \\ (中国科学院昆明动物研究所, 国家实验动物云南灵长类中心联合实验室, 昆明 650107)
}

\section{关键词 猕猴、卵母细胞、体外受精}

卵母细胞成熟的调控机制, 胚胎的发育与分化是生殖机理研究中最重要而尚不够清楚的 问题. 自 Pincus 和 Enzmann ${ }^{[1]}$ 首次体外培养卵母细胞成功以来, 体外受精已在家畜和人类 的研究中取得很大进展. 尽管世界上已有超过 5000 名 “试管婴儿” 诞生 ${ }^{[2]}$, 但进一步的研究受 伦理、法律和实验条件的限制. 基于非人灵长类在生理上与人类的极其相似的特征, 非人灵长 类的体外受精的研究不仅是解决人类的不育, 也是解决受精机制(包括精、卵的成熟调控)、胚 胎发育、植入和遗传病理最有效的工具. 卵母细胞的成熟是体外受精的首要问题, 它可能受到 激素、生化物质和培养条件等多方面因素的影响 ${ }^{[3]}$. 采用外源性激素超数排卵进行体外受精 已在猕猴、松鼠猴中有所报道 ${ }^{[4]}$. 非激素刺激卵的体外培养及受精报道很少 ${ }^{[]}$, 促进卵母细胞 的体外成熟是尚待解决的关键问题, 这与受精率和胚胎的发育分化密切相关 ${ }^{[3,6]}$. 为评价促性 腺激素对卵母细胞成熟和胚胎发育的影响, 本文就促滤泡生成素 (FSH) 对非激素刺激的猕 猴( Macaca mulatta) 卵母细胞成熟的影胁, 以及体外受精后胚胎的发育进行了比较研究.

\section{一、材料和方法}

12 只性成熟, 在生殖季节但月经周期不清楚, 未经任何药物处理而用于制药工业的猕猴, 在其被处死 1-2h 内取出卵巢, 放入 TALP-HEPES(TH) 培养液 ${ }^{[4,6]}$, 在室温无菌条件下剖 开挑取卵母细胞. 将挑出的无卵丘或带少量卵丘细胞的卵母细胞分为两组, 分别移人已在 $37^{\circ} \mathrm{C}, 5 \% \mathrm{CO}_{2}, 95 \%$ 空气中平衡过夜的两种培养液中:（1） TALP + 0.3\% BSA（牛血清 白蛋白) $+20 \% \mathrm{HCS}$ (人胎盘脐带血清); (2) TALP + $0.3 \% \mathrm{BSA}+20 \% \mathrm{HCS}+10 \mu \mathrm{g} / \mathrm{ml}$ FSH-P (动物垂体促滤泡生成素). 每隔 $24 \mathrm{~h}$ 进行观察和更换新鲜培养液. 当卵母细胞出现 清晰的卵周间隙 (PVS) 或第一极体 (PB1) 时, 即进行体外受精. 精液的采集用阴茎电刺激 采精法. 精液的处理参照 Bavister 等 ${ }^{[5]}$ 和 Lanzendorf 等 ${ }^{[4]}$ 报道的方法稍加修改 (用 $\mathrm{pH} 7.4$ 的 TH 清洗两次), 然后移人含 $0.3 \% \mathrm{BSA}$ 的 TALP 中, 加入 $0.2 \mathrm{mmol} / \mathrm{L} \mathrm{dbcA} \mathrm{MP}$ 和咖啡 因, $37^{\circ} \mathrm{C}$ 获能 $1-1.5 \mathrm{~h}$ 。最终精子受精浓度约为 $10^{5} / \mathrm{ml}$. 精、卵在含 $2 \% \mathrm{HCS}$ 的 TALP $+0.3 \%$ BSA 的培养液中受精. 6-18h 内观察卵内是否形成两个原核或第二极体判断受精情况. 受 精卵移至生长培养液 (TALP + $0.3 \% \mathrm{BSA}+20 \% \mathrm{HCS})$ 中继续培养. 受精率按受精卵发育 至 2 细胞以上胚胎计算, 用卡方检验统计。

1991 -03-14 收稿, 1992-06-25 收修改稿

* 本研究得到美国洛克菲勒基金会和云南省应用基础基金及昆明动物研究所所长基金的资助 


\section{二、结果与讨论}

12 只狝猴的卵巢共获得 568 个卵母细胞. 其中约 $65 \%$ 为包裹多层卵丘细胞等 极不成 熟的卵. 本研究所挑取的 200 个带单层或无卵丘的卵母细胞中, $57 \%$ 在 $24-96 \mathrm{~h}$ 后出现

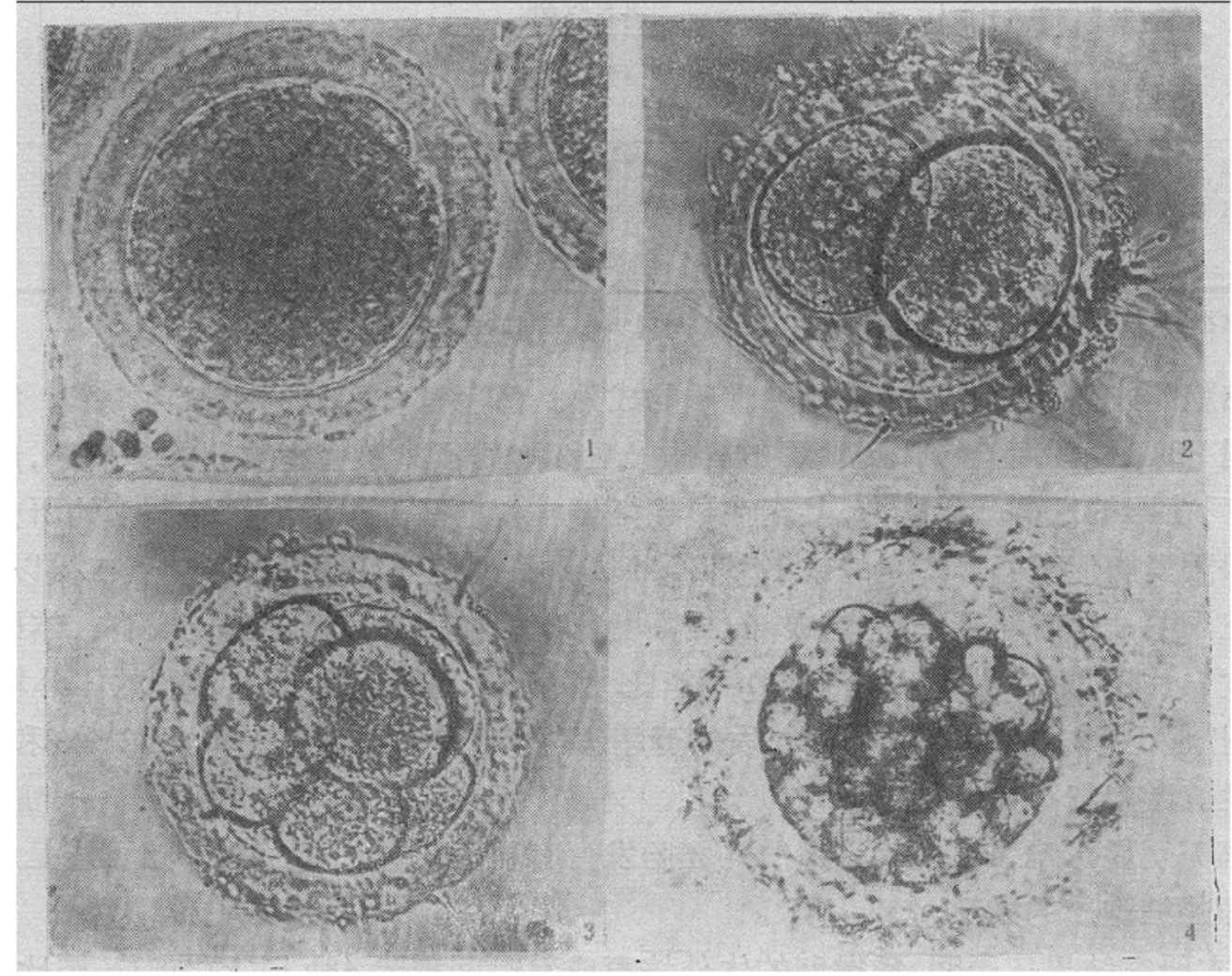

图 1

1. 培养 $72 \mathrm{~h}$ 后出现第 1 极体 ( $\mathrm{PB} 1$ ) 和卵周间隙清晰的卵, 2. 两个细胞的胚胎, 3.八个细胞的胚胎, 4 . 早期桑椹胚. $\times 320$

PVS 或 PB1 (图 1-1). 其中多数在培养 $72 \mathrm{~h}(28.6 \%$ ) 和 $96 \mathrm{~h}(50.0 \%$ ) 成熟(图 2). 加 FSH 处 理的卵与不加 FSH 处理的卵的受精率并无显著差异 (分别为 $39.8 \%$ 和 $30.8 \%$ ); 但 前 者 在受精后发育至 $16-32$ 细胞的胚胎 $(82.8 \%)$ 显著高于后者 $(18.2 \%$, $p<0.01$, 表 1). 发育至不同阶段 (2 细胞, 4-8 细 胞, 早期桑椹胚) 的胚胎见图 1-1-4.

在非人灵长类体外受精的研究中, 利用激素超数 排卵固然可以得到一些质量较好的卵, 但是也存在一 些不利因素：（1）比起自然发生的卵, 其滤泡液中激 素含量不正常; (2) 超排的不可重复性 ${ }^{[5]}$. 如果能把 自然发生的卵在实验控制条件下培养成熟, 无疑将对 了解卵成熟的调控机制乃至受精机理都是十分有用 的. Morgan 等 ${ }^{[6]}$ 报道了从活体猕猴切除卵巢取卵. 本文结果显示, 从处死后 $2 \mathrm{~h}$ 的狝猴所获得的卵, 可以 在体外培养成熟、受精和发育至早期桑想胚. 这有可

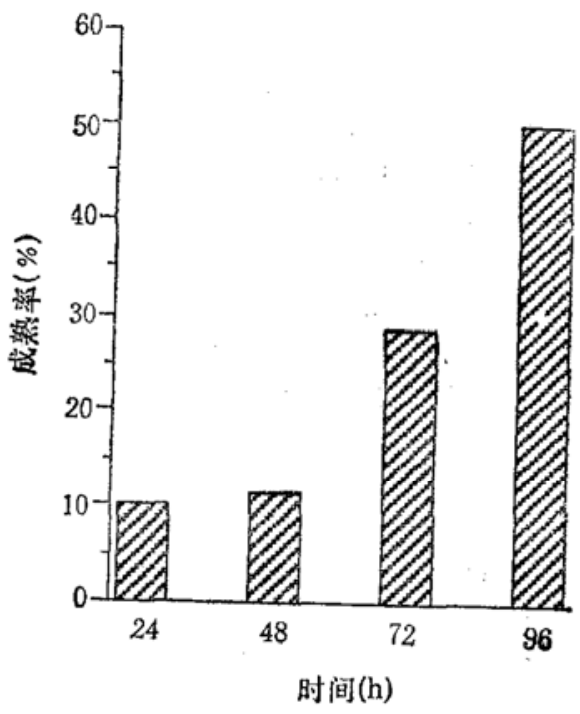

图 2 受精成功 (发育至 2 细胞以上) 的卵在不同时间成熟率的比较 
能为研究卵成熟的调控机制和受精机理以及胚胎的发育分化和着床机理提供更多的实验材 料。

表 1 狝猴卵的体外培养成䓡、受精和发育

\begin{tabular}{|c|c|c|c|c|c|c|}
\hline \multirow[b]{2}{*}{ 培养液 } & \multirow[b]{2}{*}{ 卵数 } & \multicolumn{4}{|c|}{ 发育时期 } & \multirow{2}{*}{ 受精率(\%) } \\
\hline & & PVS/PB1 & $\begin{array}{l}2-4 \\
\text { cells }\end{array}$ & $\begin{array}{l}5-8 \\
\text { cells }\end{array}$ & $\begin{array}{c}16-32 \\
\text { cells }\end{array}$ & \\
\hline TALP + HCS + FSH & 93 & 51 & - & 6 & 31 & 39.8 \\
\hline TALP + HCS & 107 & 57 & 7 & 20 & 6 & 30.8 \\
\hline 总 计 & 200 & 108 & 7 & 26 & 37 & 35.0 \\
\hline
\end{tabular}

a) 受精率指发育 2 个细胞以上(含 $2 \cdots$ 细胞)的肧胎与采集到的卵的总数相比

卵母细胞的成熟包括核的成熟和细胞质的成熟. 前者有较明显的形态学特征, 如生发泡 破裂或出现 PB1, 而后者至今尚无明显的标志 ${ }^{[7]}$. 细胞质不成熟会影响卵的受精率, 产生多精 登精, 降低受精卵的发育分化能力, 甚至在早期妊娠中死亡等. 体内和体外受精的研究结果表 明, 促性腺激素能促进卵母细胞的成熟 ${ }^{[4-7]}$. Morgan 等 ${ }^{[6]}$ 对成熟度较低(包裹二层以上卵丘) 的卵的研究表明, FSH 能促进卵的成熟, 提高受精率, 并促进了受精卵的发育. 本研究所用 卵的成熟度 (不带或仅带少量卵丘细胞) 可能比 Morgan 等所用者为高, 卵的体外培养成熟 (108 个卵出现 PVS 或 PB1) 以及成熟后的受精率(两组不同培养液分别为 $72.5 \%$ 和 $57.9 \%$ ) 都与用促性腺激素超数排卵的结果相似 ${ }^{[4,6,7]}$. 本文结果还显示, FSH 对具有一定成熟度的 卵的受精率无明显影响，但对其受精后的肧胎发育有显著的作用(表 1)。这可能是 FSH 促 进了这些卵的细胞质的成熟。

此外,本研究结果还表明,狝狔卵的体外培育成熟时间需要 $48 \mathrm{~h}$ 以上(图 2), 要比小鼠、兔 和羊等动物的长 ${ }^{[3]}$, 也比 Morgan 等 ${ }^{[6]}$ 报道的要长. 这一方面进一步证实了卵的成熟时间与 不同种类生殖周期的长短有关 ${ }^{[3]}$, 另一方面是否与培养条件(例如加人的血清)有关, 还待进一 步研究.

\section{参考 文 献}

[1] Pincus, G., Enzmann, E. V., J. Exp. Med., 62(1935),665-675.

[2] Binor, Z. et al., Gamtete Research, 19(1988), 91-99.

[3] Skoblina, M. N., Oocyze Growth zand Maturation (Eds. Delttaff, T. A., Vassetzky, S. G.), Consultants Bureau, New York, 1988, 341-392.

[4] Lanzendorf, S. E. et al., Biol. Reprod., 42(1990), 703-711.

[5] Bavister, B. D., The Primate Otyary (Eds Brenner, R. M. et al.), Plenum Press. New York, 1987, $119-137$.

[6] Morgan, P. M. et al., Biol. Reprod., 45(1991), 89-93.

[7] Boatman, D. E., The Mammalinan Prsimiantion Embryos (Ed. Bavister, B. D.), Plenum Pres, New York, 1987. 273-308. 